\title{
How About The Resilience of Students Who Have Mothers as Victims of Domestic Violence?
}

\author{
Arnaldy $^{1}$, Yarmis Syukur ${ }^{2}$, Herman Nirwana ${ }^{3}$ \\ ${ }^{1}$ Universitas Negeri Padang dan SMAN 13 Padang \\ ${ }^{2}$ Universitas Negeri Padang \\ ${ }^{3}$ Universitas Negeri Padang
}

\begin{tabular}{l}
\hline \hline Article Info \\
\hline Article history: \\
Received Dec $11^{\text {th }}, 2019$ \\
Revised Jan $13^{\text {th }}, 2020$ \\
Accepted Feb $12^{\text {th }}, 2020$ \\
\hline
\end{tabular}

\section{Keyword:}

Resiliensi

Peserta didik

Korban KDRT

\begin{abstract}
The ability in the form of individual toughness to be ready to face bitter realities is known as resilience. Resilience is needed by students, one of which applies as the child of a parent of victims of domestic violence. This research is a qualitative research with a case study approach. The study was conducted at one of the High Schools in the City of Padang. The subjects in this study were one student with criteria as a child whose parents (mother) experienced domestic violence, counseling teachers and parents of students. Taking the subject of this study using purposive sampling method. This study uses data collection techniques with interviews and observations. The technique guarantees the validity of the data carried out by building close relationships with subjects and informants naturally and continually making observations. Data analysis technique is done by data reduction, data display and conclusion drawing and verification. The results revealed that the conditions of resilience of parents (mothers) of domestic violence victims are as follows: (1) IRs have immature emotional control when dealing with domestic violence experienced by their mothers, (2) IRs have poor impulse control when dealing with domestic violence experienced by their mothers , (3) IR has good optimism when facing domestic violence experienced by his mother, (4) IR is still not good at analyzing problems carefully, (5) IR has good empathy, (6) IR has good self-efficacy, and (7) IRs have good reaching out when dealing with their mothers as victims of domestic violence. So, it can be concluded that IR has a fairly good resilience.
\end{abstract}

(C) 2019 The Authors. Published by IICET

This is an open access article under the CC BY-NC-SA license

(https://creativecommons.org/licenses/by-nc-sa/4.0

\section{Corresponding Author:}

Arnaldy,

Universitas Negeri Padang

Email: arnaldy1303@gmail.com

\section{Pendahuluan}

Peserta didik sebagai remaja akan mengalami kebingungan menghadapi diri sendiri dan sikap-sikap orang disekitarnya yang sering memperlakukan mereka sebagai anak-anak, namun sering juga menuntut mereka bertingkahlaku dewasa. Oleh karena itu, peserta didik berkeinginan untuk menyampaikan permasalahan yang dialaminya kepada guru BK/Konselor (Khofifah, Sano, \& Syukur, 2017). Peserta didik diharapkan mampu memiliki daya tahan psikis yang tinggi dalam mengahadapi permasalahannya. Jadi, individu sering menghadapi berbagai masalah dan tantangan yang tidak menyenangkan dan tidak diharapkan hendaknya memiliki sikap resiliensi yang baik.

Resiliensi merupakan kemampuan individu dalam belajar menghadapi segala realita kehidupan yang tidak menyenangkan (Albuquerque, Almeida, Cunha, Madureira, \& Andrade, 2015). Resiliensi pada individu 
ditandai dengan sikap memiliki usaha untuk belajar dan menyesuaikan diri dengan keadaan kepada yang lebih baik (Ifdil \& Taufik, 2012). Jadi, resiliensi adalah kemampuan individu untuk dapat menghadapi dan beradaptasi dari berbagai kondisi kenyataan permasalahan yang berat. Resiliensi juga disebut sebagai kemampuan daya lentur untuk dapat bangkit dari berbagai kondisi keterpurukan.

Resiliensi bertujuan untuk mengarahkan individu agar siap menghadapi kesulitan hidup akibat dari, misalnya peristiwa bencana atau musibah, kasus kekerasan, kegagalan hidup membina hubungan, kondisi brokenhome, kondisi-kondisi stres, trauma dan kondisi penuh resiko lainnya (Werner, 2005). Resiliensi dapat diukur sesuai kondisi pengalaman peristiwa dan permasalahan yang dialami. Salah satu contohnya resiliensi dalam pasca bencana. Penelitian yang dilakukan terhadap peserta didik sebanyak 378 orang tingkat SMA seSumatera Barat pasca bencana, terbukti sebagian besar peserta didik memiliki resiliensi yang tinggi (Erwinda, Syahputra, Fadli, \& Zola, 2018).

Sebaliknya, kondisi yang sangat penting memerlukan resiliensi peserta didik yaitu ketika dihadapkan pada permasalahan keluarga yang mana peserta didik merupakan anak yang menyaksikan ibunya sebagai korban KDRT. Sejatinya, tujuan pembentikan keluarga agar setiap anggota keluarga saling merasakan ketentraman, kasih sayang dan rasa ci nta (Ainiyah \& Mufarida, 2019). Keluarga merupakan tempat pertama anak memperoleh pendidikan berupa bimbingan dan pengasuhan yang layak (Aressa, Nirwana, \& Bentri, 2016). Peran ayah di dalam keluarga yang semestinya memberi pendidikan kepada anaknya, kenyataannya memperlakukan kekerasan terhadap ibunya.

Kekerasan dalam rumah tangga diatur dalam Undang-undang Pasal 1 No. 23 tahun 2004 tentang Penghapusan Kekerasan dalam Rumah tangga adalah setiap perilaku yang terjadi terhadap seseorang terutama perempuan, yang berdampak timbulnya penderitaan secra fisik, psikis, seksual dan/atau penelantaran ruamah tangga dalam lingkup rumah tangga yang melawan hukum (Mudjiati, 2008). KDRT secra umum banyak terjadi di daerah perkotaan yang umumnya kasusnya belum dilaporkan kepada kepolisian maupun ke pusat layanan kesehatan karena cendrung kasus bersifat privasi (Field, Onah, Heyningen, \& Honikman, 2018).

Dampak penderitaan KDRT tidak hanya penderitaan terhadap istri, namun berdampak besar juga terhadap anak. Anak-anak dapat mengalami penderitaan dalam menyaksikan kekerasan terhadap ibunya dan juga dapat mengalami penderitaan secara langsung baik secara fisik maupun secara emosional (Kusumah, Dwi Putri, \& Mulyadi, 2017). Hasil penelitian tentang dampak KDRT terhadap kejiwaan anak terbukti bahwa, pengaruh KDRT terhadap perkembangan kejiwaan anak-anak berupa saling mempercayai satu sama lain dibandingkan dengan orang tua, komunikasi verbal dan nonverbal dalam menyikapi KDRT, perubahan perilaku yang meliputi penyimpangan perilaku terhadap baik atau buruk, mencari kebahagiaan di luar keluarga, depesi dan keputusasaan sehingga timbul konsep kehidupan setelah mati yang akhirnya memutuskan untuk bunuh diri (Aeny, 2017). Artinya, KDRT dapat berdampak penderitaan yang cukup besar terhadap anak.

Berdasarkan penjelasan di atas, dapat dicermati bahwa akibat yang ditimbulkan dari kesaksian anak terhadap ibu yang mengalami KDRT berdampak pada anak, sehingga peneliti ingin mendeskripsikan seperti apa resiliensi anak yang menghadapi kesaksian KDRT ayah terhadap ibunya. Anak sebagai individu yang merasakan penderitaan kdrt terhadap ibunya sangat membutuhkan dukungan dan bantuan dalam bentuk konseling dan support group.(Afdal et al., 2019). Melalui bantuan dan dukungan tersebut diharapkan seorang anak dapat mengembangkan daya resiliensinya.

Individu yang teliti merupakan peserta didik yang mengalami masalah sebagai anak yang berasal dari ibu yang mengalami kekerasan dalam rumah tangga (KDRT). Peserta didik berinisial IR sejak kecil sering menyaksikan KDRT yang dialami ibunya baik kekerasan dalam bentuk fisik dan verbal. Akibatnya, berdampak pada psikologis dari aspek resiliensi diri. Peneliti sangat tertarik untuk mengkaji resiliensi pserta didik yang berasal dari orangtua (ibu) korban KDRT.

\section{Metode}

Penelitian ini termasuk pendekatan kualitatif dengan jenis studi kasus. Penelitian studi kasus adalah penelitian yang bertujuan mengembangkan analisis secara mendalam dari sebuah kasus tunggal atau kasus jamak (Creswell, 2007). Studi kasus mengutamakan eksplorasi dari suatu sistem yang saling terkait satu sama lain dalam beberapa hal satu kasus secara mendetail, disertai dengan penggalian data secara mendalam yang melibatkan dari beberbagai lini yang kaya akan konteks (Herdiansyah, 2015). Peneliti dalam kualitatif bertindak sebagai instrumen penelitian yang memberikan gambaran tentang kondisi secra faktual dan sistematis fenomena yang dimiliki (Moleong, 2007). 
Teknik pengambilan data melalui wawancara dan observasi. Responden dalam penelitian merupakan seorang peserta didik yang sedang bersekolah di SMA di Kota Padang. Sedangkan informan tambahan dengan teknik snowball, dengan maksud mendapatkan data yang pada mulanya sedikit menjadi semakin lama semakin besar dari keterangan informan tambahan (Miles \& Huberman, 1992). Informan tambahan berasal dari ibu dari subjek, Kakak kandung ibunya, guru dan teman sebaya. Adapun nalisis data dengan mengikuti reduksi data, penyajian data dan kesimpulan.

\section{Hasil dan Pembahasan \\ Hasil}

Temuan penelitian ini mendeskripsikan tentang aspek-aspek kondisi resiliensi individu. Penelitian ini mengungkap resiliensi peserta didik berjenis kelamin perempuan berinisial IR berasal dari ibunya yang mengalami KDRT, yang terdiri dari, (1) pengaturan emosi, (2) kontrol terhadap impuls, (3) optimisme, (4) kemampuan menganalisis masalah, (5) empati, (6) efikasi diri dan (7) reaching out.

IR merupakan anak sulung dari tiga orang bersaudara. IR lahir pada tahun 2002 dan berdomisili di Padang. Ayah bekerja sebgai ASN di Puskesmas dan Ibu seorang penjual lontong di depan teras rumah. IR menyaksikan ibunya menjadi korban KDRT dari Ayahnya sejak IR berusia 3 tahun. IR menyaksikan ibunya ditampar, ditendang bahkan hingga kekerasan dalam bentuk seksual. Selain itu, IR sejak kecil usia 3-10 tahun beberapa kali juga mengalami kekerasan verbal dan kekerasan fisik.

Perolehan data-data yang didapatkan oleh peneliti beberapa kali melalui kegiatan konseling. Konseling dilakukan baik di ruang konseling maupun di halaman sekolah. Kemudian, peneliti senantiasa membangun raport dengan klien (IR) dengan menumbuhkan rsa nyaman dan akrab agar klien terbuka dalam mengemukakan masalahnya. Klien (IR) datang sendiri kepada konselor karena sering merasa tidak konsentrasi dalam belajar. Ternyata, setelah digali, maka klien (IR) mengalami kesedihan dan kemarahan karena pengalaman KDRT yang dialami ibunya.

\section{Pembahasan \\ Pengaturan Emosi}

Awal IR menyaksikan KDRT yang dialami ibunya disebabkan karena ibu IR dianggap melakukan selingkuh dengan kakak iparnya. Tuduhan ayah terhadap ibunya sampai saat ini masih dilontarkan kepada ibunya. IR berkata "Papa sering main tangan ke mama berkata kasar dan sering menuduh mama berzina dengan kakak iparnya" "Papa sering main tangan ke mama dan berkata kasar serta sering menuduh mama berzina degan kakak iparnya"). Pak, IR waktu ketek acok nampak mama dilampang papa. Sampai akhir-akhir ini pak, IR acok tengah malam tajago mancaliak kondisi mama apakah kanai pukul jo papa" ("Sampai akhirakhir ini pak, IR sering tengah malam terbangun melihat kondisi mama dipukul papa"). Kalau IR indak manjago mama tengah malam nampak se kadang ado memar di pipi mama" ("Kalau IR tidak menjaga mama tengah malam tampak saja kadang ada mamr di pipi mama"). Disitulah IR sangat benci dan emosi jo papa" ("Di situlah IR sangat benci dan emosi dengan papa"). Sampai kini IR ndak menganggap papa sebagai kapalo rumah tangga dan IRmuak bana" ("Sampai saat ini IR tidak menganggap papa sebagai kepala rumah tangga dan Ir sangat muak pak").

(WR 07092019).

Selanjutnya, peneliti mengadakan wawancara dengan salah satu Guru BK yang pernah konseling dengannya sekaligus diskusi profesional. Guru BK mengungkapkan bahwa IR mengaku ibunya menjadi korban KDRT. IR menceritakan kekhawatiran dirinya terhadap kondisi ibunya yang begitu menderita atas perlakuan ayahnya. Berdasarkan penjelasan yang disampaikan oleh guru BK bahwa ketika ibunya mengalami KDRT, IR begitu sangat sedih terhdap ibunya. Kemudian, IR juga muncul perasaan marah dan benci terhdap ayahnya sehingga setiap malam IR sering tidak tenang dengan kondisi ibunya.

Temuan hasil observasi yang peneliti lakukan di sekolah saat PBM dan di luar PBM terhdap IR, bahwa IR pernah beberapa kali berbicara dengan kasar dan nada tinggi kepada teman-temannya jika terjadi konflik dan pertentangan dengan teman-temannya. IR berlaku begitu merasa berkuasa dan dapat memarahi temantemannya kapan saja. Sebaliknya, secara emosionl IR malah begitu cair bergaul dengan banyak teman yang laki-laki.

Berdasarkan hasil wawancara dan observasi terhadap IR, terungkap bahwa IR memiliki pengaturan emosi yang kurang baik. Adapaun bentuk pengaturan emosi tersebut ketika IR sejak kecil medapati ibunya sering mengalami kekerasan oleh ayahnya. Hal lain juga terlihat saat IR bergaul dengan teman-teman di sekolah. Sebaiknya IR memiliki pengaturan emosi yang baik dalam menghadapi situasi yang negatif.

\section{Kontrol terhadap impuls}

IR menceritakan bahwa, "kalau IR pak, nampak dan mandanga mama kanai pukul atau dicaci maki samo papa, IR lawan inyo tu pak" (Kalau Ir pak, jika terdengar atau melihat mama kena pukul atau dicaci maki, IR lawan dia pak"). Apalagi sejak awal SMP IR lah ikuik latihan Pencak Silat" ("Apalagi, sejak SMP IR sudah ikut latihan Pencak Silat"). "IR acok malawan ka papa dengan seperti iko pak, alah nu "ang" siksa 
lo mama den. "Kini, ang jan cubo-cubo malampang mama den lai" ("Sekarang jangan lou/kamu jangan cobacoba memukul mama lagi"). "Alah tuh, caraikan se mama den lai" (Sudahlah, ceraikan saja mama saya"). IR kalau ndak tahan, ingin mampacarui'an inyo (papa) tu pak ("IR jika tidak sabar lagi sering mencarut kepada papa"). (WW11092019). Begitu juga hasil observasi yang didapatkan bahwa IR mudah merspon dengan reaktif seperti kesal dan marah ketika peneliti sedang berbicara teralihkan oleh panggilan dari guru lain atau juga ketika pembicaraannya dipotong, maka IR langsung ekspresi wajahnya kesal. Selain itu, data observasi di rumah IR, ternyata IR mudah berbicara nada keras kepada ibunya ketika ada pendaatnya yang tidak diterima. (WW18092019).

Pada wawancara selanjutnya, IR mengatakan bahwa, "kalau awak bosan dan suntuak karano papa ribuik dan menganiaya mama, IR kadang-kadang terdorong untuk mencalaiak video-video porno pak ("kalau saya bosan dan suntuk karena papa ribut dan menganiaya mama, IR kadang-kadang terdorong untuk melihat video-video porno pak"). Kalau dulu waktu SMP sering jadi kebiasaan IR pak". Tapi kini IR barusaho untuk mengalihkan ke kegiatan ekskul seperti pencak silat dan pramuka ("Kalau dulu ketika SMP sering jadi kebiasaan"). ("Tapi, sekarang berusaha untuk mengalihkan ke kegiatan ekskul seperti pencak silat dan pramuka").

Jadi, dalam pengendalian dorongan impuls secara ideal individu mampu mengelola perubahan emosi reaksi dari luar dirinya (Reivich, K., \& Shatté, 2002). Sebalikknya IR memiliki pengendalian dorongan impuls masih kurang baik. Terbukti dari hasil wawancara dan observasi, IR cepat mengalami perubahan emosi yang sulit terkontrol, misalnya mudah menjawab dengan kata-kata kasar dan ekspresi emosi yang nampak jelas dari suasana nyaman tiba-tiba sulit menahan amarah ketika ada peristiwa yang tidak menyenangkannya. Termasuk juga, dorongan untuk menonton tayangan yang berbau pornografi sulit untuk dikontrolnya.

\section{Optimisme}

Temuan penelitian terhadap IR terungkap beberapa pernyataan dalam wawancara bahwa, "IR ingin bana kuliah pak kalau bisa di jurusan Hukum" ("Ir ingin betul kuliah, kalau bisa di jurusan Hukum"). "Tapi pak, IR mesti barusaho pak kalau paralu ndak masalah sebelum kuliah IR siap untuk karajo dulu setelah itu pitinyo untuak kuliah pak" ("Tapi pak, Ir harus berusaha, jika perlu sebelum kuliah IR siap untuk bekerja dulu setelah itu uangnya disimpan untuk kuliah"). (WW201119). Begitu juga, wawancara selanjutnya tentang aktivitas akademiknya, "IR iyo acok keletihan dan mangantuak pak katiko baraja di kelas pak, tapi pak IR taruih buek tugas semamunyo pak waalaupun talambek mengumpulkannyo pak" ("IR iya sering keletihan dan mengantuk pak ketika belajar di kelas, tapi pak, terus-menerus IR mengerjakan tugas semampunya pak walaupun terlambat mengumpulkannya pak"). "Kemudian pak, kalao IR ado tugas kelompok, IR slalu kebagian yang mangarajoan surang karano kawan-kawan acok lapeh tanggung jawab pak" ("Kemudian pak, jika ada tugas kelompok, pasti biasanya IR yang mengerjakan sendiri yang lainnya tidak bertanggung jawab"). "Tantu pak, mau ndak mau harus IR karajoan kalau indak yo nilai awak ndak tuntas pak" ("Tentu pak, mau tidak mau harus IR kerjakan kalau tidak ya nilai tidak tuntas"). Awak jujur sepak, IR suko acok buek tugas di sekolah pak kalau tugas pribadi, karena pak indak sempat dan binguang surang manyalasaikannyo tambah acok susah lalok malam" (Saya jujur saja pak, IR suka mengerjakan tugas di sekolah, karena tidak sempat dan bingung sendiri menyelesaikannya, tambah lagi tidak sulit tidur malam. (WW021219)

Berdasarkan hasil temuan yang didapatkan dapat disimpukan bahwa IR memiliki optimisme yang tinggi dalam menjalani hidup. Hal ini ditandai dengan masih cukup semgat untuk menyiapkan diri memasauki pendidikan perguruan tinggi. Selain itu, IR masih berusaha menikuti PBM dan menyelesaikan tugas pelajaran walaupun tantangan permasalahan keluarga masih dialaminya. Sikap optimesme dalam menghadapi mermasalahan merupakan feeling of superiority yang dimiliki individu (Corey, 2013). Oleh karena itu, individu yang optimistis merupakan individu yang dapat mengubah feeling of inferiority menuju feeling of superiority.

\section{Kemampuan menganalisis masalah}

Peneliti melakukan wawancara dengan IR, " ba'a parasaan IR ketiko mengetahui bahwa mama jadi korban KDRT?" (Ir, bagaimana perasannya ketika mengetahui bahwa mama menjadi korban KDRT")? IR sendiri menyaksikannyo sejak ketek" (IR sendiri menyaksikannya sejak kecil)." Ibo ati awak pak (sambil menangis), menderita bana mama pak" (kasihan mama, menderita terus"). "Tapi, mau bagaimana lagi pak". Yo itu pak katiko itu mama dituduah ber selingkuh jo kakak iparnyo" (Mau bagaiman lagi, alsannya mama dituduh selingkuh dengan kakak iparnya". (WW101119).

Kemudian saat observasi di kelas, IR ketika ada sesuatu peristiwa permasalahan di kelas dengan teman maupun guru, maka peneliti mengamati reaksi yang emosi yang tinggi dalam bentuk menentang dengan kata keras dan bahasa tubuh melawan tanpa harus menaganalisis penyebabnya. Begitu juga observasi saat di rumah ketika berkomunikasi dengan adiknya, maka IR langsung memarahi adiknya ketika adiknya melakukan kesalahan tanpa menanyai sebabnya terlebih dahulu.

Berdasarkan hasil wawancara dan observasi, maka IR memiliki kemampuan menganalisis masalah masih kurang matang. Seyogyanya, individu yang memiliki resiliensi yang matang adalah mampu menganalisis penyebab permasalahan terjadi (Khotimah, 2018). Kenyataannya, IR begitu langsung reaktif 
secra emosi dengan berkata kasar serta berusaha melawan ketika terjadi pertentangan dengan ayahnya. Ketika IR mnegetahui dan menyaksikan langsung KDRT yang dialami ibunya, IR langsung sangat membenci dan tidak mau patuh kepada ayahnya.

Empati

Hasil observasi saat kunjungan rumah yang peneliti lakukan, terungkap bahwa saat ibunya berjualan lontong, maka IR berusaha membantu mengasuh adiknya dengan cara menggendong dan mengajak main adiknya yang paling kecil agar ibunya tetap berjualan. Kemudian pernyataan dalam wawancara yang didapatkan bahwa, IR mengatakan "yo IR sangat ibo bana jo mama pak, masak, lah begitu acok kanai tangan jo papa, tapi mama bertahan juo ndak ado kato ingin menuntut carai ka papa" (ya, IR sangat kasihan pada mama, masa sudah begitu sering dipukul, tapi mama bertahan juga tidak ada kata ingin menuntut cerai ke papa"). (WW030120). "IR sejak itu pak tidak tega kalau bersikap kasa ka mama."Bia selah IR melawan dan bakato kasa ke papa asal ka mama indak, karano mama lah sangat marasai pak" "IR sejak itu tidak tega kasar pada mama, biar saja IR kasar kepada papa asal ke mama tidak"). Begitu juga saat wawancara, bahwa "awak kalau jo kawan inginnyo samao raso pak, contonya awak mudah meminjamkan pitih ka kawan tu pak kalau inyo nenar butuh" (saya kalau dengan teman-teman ingin sama rasa, contohnya saya bersedia meminjamkan uang kepada teman yang membutuhkan").

Berdasarkan pemahaman peneliti tentang empati maka, terungkap bahwa IR memiliki empati yang bagus. Hal ini sesuai dengan pernyataan yang disampaikan IR merasa kasihan kepada ibunya dan tidak tega jika berkata kasar kepada ibunya. Selain itu, empati kepada teman yang mengalami kesusuhan, maka IR segera membantunya.

\section{Efikasi diri}

Berkut efikasi diri yang peneliti dapatkan, ketika peneliti menanyakan harapan dan cita-cita, IR mengungkapkan "awak masih punyo harapan pak dan ingin iko berakhir". Cita-cita awak ingin kuliah walau sambil karajo pak" ("saya berharap ini semua akan berakhir"), karano selama ini penghasilan papa lewat gajinyo lah banyak dipotong, kemudian mama paling sekitar 300ribu sampai 500ribu dari hasil penjualan pak" (saya ingin kuliah walau sambil bekerja, karena penghasilan papa dari gaji banyak dipotong, kemudian penghasilan mama sekitar Rp. 300.000,- hingga Rp. 500.000,-"). Tambah lagi pak keluarga besar mama ingin mengambil alih rumah papa yang di Air pacah karena masih atas nama kakak mama" sehinggo masih jadi sengketa pak" ("Tambah lagi pak, keluarga mama ingin mengambil alih rumah papa yang di Air Pacah karena atas nama kakak mama kepemilikannya, sehigga masih disengketakan"). Paninag IR pak, tapi IR akan berusaho kareh pak setelah tamat SMA ko" (Pusing IR pak, tapi IR akan berusaha keras pak setelah tamat SMA ini"). Kemudian wawancara selanjutnya melalui media sosial, bahwa IR menyatakan, "pak, minta tolong pak carian IR karajo yang bisa masuk sore sampai malam" (Pak, minta tolong carikan IR pekerjaan yang bisa masuk sore hinggga malam"). Misalnyo pak, karajo di kafe yang gajinya nanti bisa IR tabung dan sebagian untuk mama" (Misalnya, kerja di kafeyang gajinya dapat untuk IR tabung dan sebagian untuk mama") . Begitu juga bertemu disekolah, IR selalu menanyai informasi pekerjaan untuknya. (WW181119).

Berdasarkan pemahaman definisi tentang efikasi diri dari hasil wawancara terungkap bahwa IR memiliki efikasi diri yang cukup baik. Bentuk efikasi diri IR yaitu memiliki cita-cita dan harapan hidup yang tinggi. Kemampuannya untuk mewujudkan cita-citanya di msa depan sangat tinggi.

\section{Reaching Out}

Awal pengalaman kekerasan yang diderita ibunya saat wawancara IR mengungkapkan, "IR waktu itu sempat beberapa kali berpikia ngin bunuh diri pak" (IR beberapa kali berpikir ingin bunuh diri pak"), tapi selalu terhalang oleh pikiran ibo ka mama ("Tapi selalu terhalang karena kasihan dengan mama"). Setelah itu pak, IR mulai sadar pak, kalau berakhir dengan jalan itu tandonyo IR putus asa ndak namua bangkit dari masalah barek ko pak" jadi jalan satu-satunyao pak IR harus membahagiakan mama sampai mama tuo ("Setelah itu, IR sadar pak, jika mengakhirinya maka IR sama saja putus asa tidak mau bangkit dari masalah berat ini, jalan satu-satunya IR harus membahagiakan mama"). (WW15102019).

Kemudian peneliti melakukan wawancara triangulasi kepada mamanya dan kakak mamanya (dengan panggilan mami). Pertama, saat wawancara dengan mamanya yang merupakan sebagai korban KDRT. "Saat awak bacerita-cerito ke IR ("Saat saya bercerita-cerita dengan IR), IR sedih bana pak dan ndak manarimo perilaku papanyo ke awak" bahkan sangaik banci ke papanyo" (IR sangat sedih karena perlakuan papanya ke saya dan bahkan IR sanagt benci papanya). Tapi, inyo urangnyo gigiah untuk bangkit memperbaiki nasib keluarga terutama untuak adiak-adiak dan mamanyo pak" (Tapi IR begitu tegar dan gigih untuk bangkit memperbaiki nasib untuk keluarga). (WW0912190). Senada juga dengan wawancara kepada kaka ibunya yang biasa dipanggil mami. Mami menyatakan bahwa, "iyo sangat barek yang dialami IR sejak ketek merasakan ibunya kanai KDRT" (Iya sangat berat yang dialami IR sejak kecil merasakan KDRT yang dialami ibunya). "Ambo, bukan berarti lapeh tangan untuak mancari bantuan, namun dikarano papanyo menganggap buruak keluarga ambo jadinyo taputuih komunikasi untuk membantunyo" ("saya bukan berarti lepas tangan, namun papanya sudah mengangggap buruk keluarga kami sehingga komunikasi terputus untuk membantu IR"). 
"Apalagi papanyo acok menuduah mama IR selingkuh dengan suami ambo" ("Apalagi papanya sering menuduh mama IR selingkuh dengan suami saya"). Kemandirian inyo untuak ndak menyerah dengan keadaan ambo salut ka IR pak" (" Kemandiriannya untuk tidak menyerah dengan keadaan, saya salaut pada IR pak"). (WW171019 via telepon whatsapp)

Berdasarkan wawancara triangulasi yang didapatkan, terdapat Reaching Out yang cukup tinggi. Pada dasarnya individu yang memiliki resiliensi yang baik, maka individu mampu memahami dirinya dan menetukan arah tujuan hidup yang bermakna (Reivich, K., \& Shatté, 2002). IR tidak mudah berputus asa untuk bangkit dari segala kondisi terpuruk yang dialami ibunya. IR berusaha mandiri memandu adik-adiknya untuk membantu ibunya.

\section{Peran Konselor dan Implikasinya dalam Konseling Peran Konselor}

Peranan konselor yaitu menciptakan kondisi aman dan komitmen dipegang teguh sehingga dapat mengungkapkan secara sukarela dan terbuka, didengarkan dan mendapatkan dukungan (Corey, 2013). Konselor diharapkan hadir membangun pentingnya kontak psikologis yang empatik dan individu merasa dihargai dan diakui keberadaannya (Brammer, L.M \& Shostrom, 1982). Esensinya, konselor yang empatik hendaknya mampu berperan sebagai pribadi yang disenangi dan dipercaya oleh klien (Nirwana, 2012). Konselor membantu dalam upaya terapi terhadap klien yang mengalami permasalahan menyaksikan KDRT yang dialami ibunya.

\section{Pendekaan Konseling \\ Pendekatan Psikoanalisis}

Pendekatan konseling yang dilakukan peneliti adalah pendekatan psikoanalisis klasik dan humanistik. Pendekatan psikoanalisis klasik bertujuan mengarahkan klien dari dorongan-dorongan ketidaksadaran yang mencemaskan kerah dorongan kesadaran (Purwanto, Edi, Zaenudin, Hery Bagus anggoro W, Selvia Tristianty Hidayat, 2016). Dalm hal ini IR yang mengalami ketidaksadaran pada masa kecil sering menyaksikan KDRT yang dialami ibunya sehingga IR begitu sedih dan marah yang berlebihan diarahkan pada kesadaran mengahdapi situasi saat ini dengan berusaha memaafkan ayahnya. Salah satu teknik yang digunakan yaitu asosiasi bebas. Asosiasi bebeas merupakan teknik untuk mengarahkan klien untuk mengungkapkan dan menjelasakan apa yang dirasakan dan dipikirkan yang selama ini mengganggu klien (Corey, 2013). Klien mengungkapkan perasaan-perasaan ketidaksenangannya dan penderitaannnya karena KDRT yang dialami ibunya. Keterangan yang didapat dari teknik ini terungkapnya kesaksian yang dialami ibunya sejak IR.

Adapun hasil perubahan yang dilami klien yaitu, klien (IR) mulai menyadari untuk menghadapi situasi yang selama ini sulit mengatasinya menjadi pengendalian dorongan impulsif ingin marah-marah dan berperilaku agresi kepada papanya menjadi mulai terkontrol karena selama ini sering melawan keapada ayahnya.

\section{Pendekatan Humanistik}

Penerapan konseling humanistik berlawanan dengan psikoanalisi yang mengarahkan individu sebgai koraban peristiwa yang dipengaruhi lingkungan. Sebaliknya, dalam pendekatan humanistik esensinya membangun persepsi manusia tentang realita dibanding pengalaman yang terjadi. Setiap individu dapat menentukan arah keberadaan diri yang konstruktif (Rogers dalam Purwanto, Edi, Zaenudin, Hery Bagus anggoro W, Selvia Tristianty Hidayat, 2016). Pendekatan humanistik yang diawali dengan mengarahkan pemahaman diri klien sendiri (IR) uuntuk menetukan arah kebaikan klien berdasarkan medan phenomenal yang dialaminya yaitu kesaksiannya terhdap KDRT yang dialami ibunya.

Pendekatan konseling humanistik yang dilakukan peneliti dalam wawancara konseling diawali dengan membangun hubungan awal dengan "Psychologist Contact" (Corey, 2013). Pendekatan humanistik tidak mengutamakan teknik-teknik khusus, namun kontak psikologis yang empatik dalam hubungan konseling lebih diutamakan dan menggali potenssi-potensi klien secara mandiri. Selain itu, konselor menciptakan kenyamanan dan hubungan yang akrab agar klien mampu menjelaskan permasalahannya secara terbuka (Brammer, L.M \& Shostrom, 1982).

Hasil yang didapatkan, bahwa IR berinisitaif dan berusaha memaksimalkan dirinya untuk tidak semakin terpuruk dengan keadaan. IR berusaha menerima keadaan dirinya, menentukan sikap dan tindakan yang disertai klien untuk merealisasikan pilihannya itu. Adapaun hasilnya yaitu, kepotimisan klien semakin berkembang dengan cara menjadi individu yang mandiri secara sosial dan ekonomi. Klien (IR) berusaha akan perlahan-lahan menahan diri serta memaafkan perilaku ayahnya selama ini.

Selain itu, konselor juga memadukan dengan pendekatan Adler dan karakter nilai-nilai agama. Pendekatan Adler yang diterapkan bertujuan mengarahkan klien dari Feeling of inferiority (FOI) menuju Feeling of Superiority (FOS). FOI yang dialami dalam bentuk keterpurukan dan penderitaan di masa lalu yang begitu tertekan akibat menyaksikan KDRT yang dialami ibunya sehingga menimbulkan kemarahan yang sulit dikendalikan dan juga perilaku kasar terhadap ayahnya. Kemudian, konselor mengarahkan klien (IR) kepada 
kesadaran untuk merasakan kebermaknaan hidup dan mencintai kebersamaan untuk senatiasa optimis dan bangkit dari keterpurukan. Hal ini, sejalan dengan pendekatan nilai-nilai agama dengan mengimplementasikan nilai karakter sabar dan shalat dalam mengahapi ujian. Sebagaimana dalam Al Qur'an Surat Al Baqarah ayat 153 yang artinya Hai orang-orang beriman mintalah pertolongan dengan sabar dan sholat, sesungguhnya allah mencintai orang yang sabar (Kementerian Agama Republik Indonesia, 2010). Klien perlahan menyadari dengan sabar dan memaafkan maka akan memberikan energi positif yang dapat mendatangkan optimisme dan mengubah nasib lebih baik dari kondisi keluarga yang dialaminya.

\section{Simpulan}

Hasil penelitian terungkap bahwa kondisi resiliensi peserta didik orangtua (ibu) korban KDRT sebagai berikut: (1) IR memiliki pengaturan emosi yang kurang matang ketika menghadapi KDRT yang dialami ibunya, (2) IR memiliki kontrol impuls yang kurang bagus ketika menghadapi KDRT yang dialami ibunya, (3) IR memiliki optimisme yang cukup baik ketika menghadapi KDRT yang dialami ibunya, (4) IR masih kurang baik dalam menganalisa masalah dengan matang, (5) IR mempunyai empati yang bagus, (6) IR memiliki efikasi diri yang cukup bagus, dan (7) IR memiliki reaching out yang bagus ketika menghadapi ibunya sebagai korban KDRT. Jadi, dapat disimpulkan bahwa IR memiliki resiliensi yang cukup baik. Peran konselor dalam memgimplementasikan layanan konseling begitu penting dalam mengarahkan kesadaran dan sikap resiliensi klien agar lebih baik.

\section{Ucapan Terima kasih}

Penulis mengucapkan terima kasih kepada Bapak Amriman M, S.Pd., M.M selaku Kepala SMAN 13 Padang yang telah emberikan kesempatan untuk melakukan praktik lapangan sekaligus melakukan penelitian studi kasus. Ucapan terima kasih selanjutnya, kepada Dosen Pembimbing PL Ibu Dr. Hj. Yarmis Dsyukur, M.Pd., Kons ats bimbingan dan arahannya sehingga dapat menyelesaikan rangkaian PLBK ini. Kepada Guru Pamong Ibu Narmiati, S.Pd., Kons yang membimbing selama proses prktek di sekolah. Ucapan terima kasih juga kepada orangtua dan keluarga yang senantiasa mndukung dan mendoakan penulis. Selanjutnya, kepada teman-teman seperjuangan ats kerjasama dan partsipasi demi kelancaran PLBK. Semoga penelitian ini dapat bermanfaat bagi semua pihak yang terkait di dunia BK.

\section{Referensi}

Aeny, L. I. (2017). Dampak kekerasan dalam rumah tangga terhadap perkembangan kejiwaan anak pada novel di tanah lada karya Ziggy zezsy azeoviennazabrizkie. Universitas Diponegoro Semarang.

Afdal, A., Arnaldy, A., Nirwana, H., Alizamar, A., Zikra, Z., Ilyas, A., \& Fikri, M. (2019). Increasing life satisfaction of domestic violence victims through the role of supporting group therapy on social media. Advances in Social Science, Education and Humanities Research, Volume 372, 372(ICoET), 139-144.

Ainiyah, Q., \& Mufarida, L. (2019). Kufu Agama dalam Pernikahan , Peletak Dasar Pendidikan Islam dalam Keluarga Menuju Baiti Jannati, 3(1), 19-26. https://doi.org/10.21070/halaqa.v3i1.2120

Albuquerque, C., Almeida, J., Cunha, M., Madureira, A., \& Andrade, A. (2015). Protective resilience factors in institutionalised portuguese adolescents. Procedia - Social and Behavioral Sciences, 171, $276-283$. https://doi.org/10.1016/j.sbspro.2015.01.122

Aressa, V., Nirwana, H., \& Bentri, A. (2016). Komunikasi interpersonal anak dan orangtua ditinjau dari jenis Kelamin , tingkat pendidikan orangtua , dan daerah tempat tinggal serta implikasinya pada bimbingan dan konseling. Konselor, 5(3), 1-12.

Brammer, L.M \& Shostrom, E. . (1982). Therapeutic Psychology Fundamentals of Counseling and Psychotherapy. New Jersey: Prentice-Hall.Inc.

Corey, G. (2013). Theory and practice of counseling and psychotherapy. In E. M. Seth Dobrin, Naomi Dreyer, Suzanna Kincaid (Ed.), Theory and Practice of Counseling and Psychotherapy (Ninth Edit, pp. 136169). California: Brooks/Cole Cengage Learning. Retrieved from www.cengage.com/brookscole

Creswell, J. W. (2007). Research Design. (Diana E. Axelsen, Ed.) (Second Edi). London and New delhi: Sage Publication.

Erwinda, L., Syahputra, Y., Fadli, R. P., \& Zola, N. (2018). Rasch politomy analysis : measuring the level of student senior high school resilience after the disaster in west sumatra analisis rasch. Konselor, 7(4), 138- 
144.

Field, S., Onah, M., Heyningen, T. V, \& Honikman, S. (2018). Domestic and intimate partner violence among pregnant women in a low resource setting in South Africa: A facility-based, mixed methods study. BMC Women's Health, 18(1), 1-13. https://doi.org/10.1186/s12905-018-0612-2

Herdiansyah, H. (2015). Metodologi Penelitian Kualitatif untuk Ilmu Psikologi. (Rosidah, Ed.) (1st ed.). Jakarta: Salemba Humanika. Retrieved from http://www.penerbitsalemba.com

Ifdil, \& Taufik. (2012). Urgensi peningkatan dan pengembangan resiliensi siswa di Sumatera Barat. Pedagogi, $X I I(2), 115-121$.

Kementerian Agama Republik Indonesia. (2010). Al Qur'an Tajwid dan Terjemahan. (Kementerian Agama RI, Ed.). Bandung: PT. Sygma Examedia Arkanleema. Retrieved from www.sygmacorp.com

Khofifah, A., Sano, A., \& Syukur, Y. (2017). Permasalahan yang disampaikan siswa kepada guru Bk/konselor. Jurnal EDUCATIO: Jurnal Pendidikan Indonesia, $3(1), \quad 45$. https://doi.org/10.29210/12017271

Khotimah, K. (2018). Faktor pembentuk resiliensi remaja dari keluarga broken home di desa pucung lor kecamatan kroya. Jurnal Dakwah Dan Komunikasi, 12(1), 136-157.

Kusumah, H. A., Dwi Putri, R. E. G., \& Mulyadi, A. (2017). Peningkatan pemahaman masyarakat tentang perlindungan hukum terhadap korban tindak pidana kekerasan dalam rumah tangga. Legality, 24(2), 236-243.

Miles, M. ., \& Huberman, A. . (1992). Analisis Data Kualitatif Buku Sumber Tentang Metode-Metode Baru. Jakarta: UI Press.

Moleong, L. . (2007). Metodologi Penelitian Kualitatif (23rd ed.). Bandung: PT. Remaja Rosdakarya.

Mudjiati. (2008). Undang-undang No. 23 tahun 2004 tentang Penghapusan Kekerasan dalam Rumah Tangga (UU-PKDRT). Retrieved from http://ditjenpp.kemenkumham.go.id/hukum-pidana/653-undangundang-no-23-tahun-2004-tentang-penghapusan-kekerasan-dalam-rumah-tangga-uu-pkdrt.html

Nirwana, H. (2012). Pengungkapan Diri Siswa Sekolah Menengah Dan Implikasinya Bagi Konseling. Ilmu Pendidikan, 18(1), 1-7.

Purwanto, Edi, Zaenudin, Hery Bagus anggoro W, Selvia Tristianty Hidayat, S. A. (2016). Modul Guru Pembelajar BK SMA/SMK Kelompok Kompetensi F. Jakarta: Pusat Pengembangan dan Pemberdayaan Pendidik dan Tenaga Kependidikan Penjas dan BK Dirjen Guru dan Tenaga Kependidikan Kemendikbid.

Reivich, K., \& Shatté, A. (2002). The resilience factor: 7 essential skills for overcoming life's inevitable obstacles. New York: Broadway Books.

Werner, E. . (2005). Resilience in children, families, and communities: Linking context to practice and policy. Ner York: Plenum Publisher. 